\title{
Individualised Funding and the Feminised Paid Care Workforce
}

\author{
Carol Smail*, Tony Giles \\ ACL Disability Services and Gig Buddies, Sydney, New South Wales, Australia.
}

How to cite this paper: Carol Smail, Tony Giles. (2022) Individualised Funding and the Feminised Paid Care Workforce. Journal of Humanities, Arts and Social Science, 6(1), 74-80.

DOI: $10.26855 /$ jhass.2022.01.008

Received: December 28, 2021

Accepted: January 25, 2022

Published: March 1, 2022

${ }^{*}$ Corresponding author: Carol Smail, ACL Disability Services and Gig Buddies, Sydney, New South Wales, Australia.

Email: carol@assistcom.org

\begin{abstract}
A gender imbalance in the disability and health sector, with a bias towards female health workers, may deny young males with disability the personalised care they desire. Data from the disability service industry, primary care givers, and the Gig Buddies volunteer project, has provided insight into this imbalance, with quantitative and qualitative data from over 6 years of pairing volunteers with adults with mild to moderate learning disability and/or autism. Research shows that many males with disability have little or no contact with male support or role models and have expressed the want to have a male buddy or friend to catch up with regularly. Introducing males to the disability sector, through an enjoyable and rewarding volunteer befriending scheme, and an informal introduction to the National Disability Insurance Scheme (NDIS), may help address the gender imbalance and help create a more gender-balanced paid care workforce.
\end{abstract}

\section{Keywords}

Gender, Workplace, Disability, Volunteering

\section{Introduction}

The Gig Buddies project started with a simple premise; facilitate and include people with learning disability and autism to enable real social inclusion in the music, sporting, cultural and social life of the community.

Finding professional support staff, or a willing family member, who will stay out late enough to catch the headline act at a pub gig, or at a small to medium sized venue, is a challenge many people with a learning disability face. Hanging out with your mum or a disinterested support worker at a gig isn't most people's idea of a fun night out.

\section{Inclusion and gender bias}

Paul Richards, who was in a punk band that included 3 people with learning disability in Brighton in the UK, saw the need for a new way to enable people with learning disability to stay out late, and devised the Gig Buddies volunteer program.

ACL Disability Services worked with Paul and the UK Gig Buddies team to develop the project for Australia, and in February 2015 the Gig Buddies Sydney project was launched.

As a disability organisation, ACL Disability Services were aware of the existence of many social groups which enable outings with paid staff and family.

However, these outings or events tend to be disability-specific and do not include the broader community. Furthermore, these events involve an overrepresentation of female staff and female parent of those attending.

Many people with a learning disability have small social networks that often only include immediate family, and in many cases, the primary carer is the mother. 
According to the Australian Institute of Health and Welfare (AIHW), 2004;

"In 1998, primary carers of Australian children with a disability were mostly mothers (85\% of all primary carers), followed by fathers (10\%)"

[Australian Institute of Health and Welfare (AIHW), 2004]

Although these statistics are for children with disability and not adults, research and experience has found that the primary carer for Gig Buddies participants in the 18 to 34 age bracket is still predominately a female parent.

Lack of positive male role models within the family group and in the paid workforce is an issue, particularly for males with a disability, but also for many females who may have had little or no engagement with a male parent or sibling.

In interviews with new participants, it's often found that, since leaving high school, social networks have all but dried up, with school friends heading to university or beginning a career. Young people with learning disability find they now have few opportunities in their limited social network and at disability-centric activities to make new friends.

\section{A solution to social isolation-Gig Buddies}

The Gig Buddies project matches a person with a learning disability with a volunteer. And based on a mutual passion to go to see a band, a sporting match, to the theatre or to any activity that is of shared interest, they catch up regularly, go to "gigs" and potentially develop a meaningful friendship.

As part of the Gig Buddies pairing process, project staff has interviewed over 300 participants with mild to moderate learning disability and autism from all over Sydney.

From the interviews, over half of the participants stated they often have a feeling of being socially isolated, with many suffering from depression and/or anxiety as a result.

As the project matches participants and volunteers based on shared interests and other factors like gender preference, age and locality, there is a real opportunity created for a long and sustainable relationship to flourish.

A one size fits all approach just does not work, and the project takes great care to make a buddy pairing sustainable and enjoyable for participants and volunteers alike.

The process is not as simple as finding a good match, then putting those two people together and sending them out to gigs or events. Gig Buddies volunteers are vetted; all volunteers must present a current police check (now an NDIS Worker Screening Check) and two references. Once a match is made, the volunteer attends a half day volunteer training course that covers disability education, buddy empowerment, communication exercises, risk aversion, boundaries, challenging scenarios and safeguarding. Gig Buddies staff then facilitate a pairing meeting with the buddies, where a risk assessment and formal agreement is completed. Following a successful pairing, a Gig Buddies staff member accompany the new buddies to their first gig.

Parents and support staff are included in the process where necessary, but the emphasis is on two people, (or buddies), choosing their own adventures based on their mutual interests.

In order to encourage tangible outcomes and potential friendships, volunteers are asked to commit to being a gig buddy for a minimum of one year and to catch up with their buddy at least once a month.

The social validation gained from 'having a true friend', not a person who is paid to be in your life, is powerful and obvious. Catching up regularly and attending mainstream events with a buddy who has similar interests can inspire social confidence, and potentially the development of new skills, such as navigating public transport, purchasing tickets online, taking photos, posting on social media or even gaining the confidence to strike up a conversation with a stranger at a gig.

In the article "Identifying conceptualizations and theories of change embedded in interventions to facilitate community participation for people with intellectual disability: A scoping review" by Bigby et al., 2017 (LaTrobe University, Living with Disability Research Centre),

In relation to community participation programs similar to Gig Buddies, the paper states;

"The distinguishing feature of these programmes was that the encounter occurred in public non-segregated places, or community groups or volunteer organizations with others who do not have disability.”

"The theory of change evident in these programmes was that supporting people with intellectual disability to join mainstream community groups, undertake volunteer work or engage in social interactions in commercial or public places would lead to episodic, intermittent or singular convivial encounters.” 
[Bigby et al., 2017 (LaTrobe University, Living with Disability Research Centre)]

For the volunteer, the program is mutually beneficial, with many volunteers stating that they signed up because they too wanted to get out more, or that their friends didn't like the same music as them.

From the volunteer application form, here are some answers to the question, "What makes you want to volunteer for Gig Buddies Sydney?”

“I'm go to gigs every couple of weeks anyway, so why not give someone else the opportunity while I'm at it"

"Music can ease a mind \& heart. I want to help make this difference."

"To do something for other people without requiring a reward other than personal satisfaction, doing something I enjoy, attending music gigs"

"I don't have much money to offer charity but I do have time! Why not do something that I also like doing and will do anyway"

"I like connecting with people and like the idea of helping people fight off loneliness."

"Most volunteer organisations want me to work regular hours, or for whole days at a time. I like the fact that my Buddy and I choose when we go out together.”

Most volunteers have spent little or no time interacting with a person with a disability before joining.

Those who have now been paired up have stated that their life has been enriched by the unique relationship they have with their buddy.

"Seeing how happy my buddy is, and the others at group events, when we are out. It has been some of my favourite nights out since living in Sydney.” Erin, Volunteer

Parents of participants have also praised the project and see the benefit of positive role models in their sons or daughters lives. So much so that some volunteers have been accepted into the extended family circle and in some cases have been invited to important family events, such as Christmas dinner, and in one case, a wedding.

"You guys have made such a difference in Hayes’ life. He loves his Gig Buddy Stefan so much. Stefan is amazing, he is patient, aware of Hayes' needs and is a true mate.

This really works and Hayes feels so much more independent, and his life is richer for the kindness of everyone.” Deb, mother of Gig Buddies participant

The inclusive nature of The Gig Buddies Sydney project is reflected in the user-led advisory team, The Soul Fly Band. A group of six adults with learning disability who come together monthly to advise the project moving forward.

The group has advised the project with social event choices, participant questionnaires, a code of conduct, fundraising ideas, website and training content; and they have recently met with a local security service and police department to advise on better work practice for security personnel and police officers in relation to working with adults with learning disability.

The Gig Buddies Sydney team have also been working towards creating a more inclusive environment with the creation of an LGBTQI advisory group consisting of participants and volunteers. Taking direction from the UK Gig Buddies group, "Wild Rainbows", the initiative will aim to provide information and a safe and inclusive space for LGBTQI adults with learning disability. EDIT; in early 2021, Gig Buddies Sydney marched in the Sydney Mardi Gras

Amongst the many connections the Gig Buddies team have developed within the community, recent talks with SSI (Settlement Services International) promise to make the program more accessible to people from culturally and linguistically diverse backgrounds.

\section{Gender imbalance in the disability sector}

So how can this type of volunteer program impact the gender imbalance in the disability sector?

In the Gig Buddies project, there is a definite bias in favour of female volunteers in the statistics, with the female to male volunteer percentages mirroring the gender breakdown of the Australian disability workforce, at approxi- 
mately $70 \%$ female to $30 \%$ male, as shown in the table; “Gender-Disability vs. Gig Buddies volunteers” (Figure 1).

As this volunteer project was originally centred around going out to live music or "Gigs", the project staff have not been surprised by the enthusiasm of volunteers, all who have a passion for music and going out to events. Although the percentage of recruited male volunteers unfortunately has not exceeded the percentage of males in the disability workforce, the NEED for male volunteers is apparent when looking at the breakdown of male to female participants.

DISABILITY INDUSTRY (2017) - GENDER

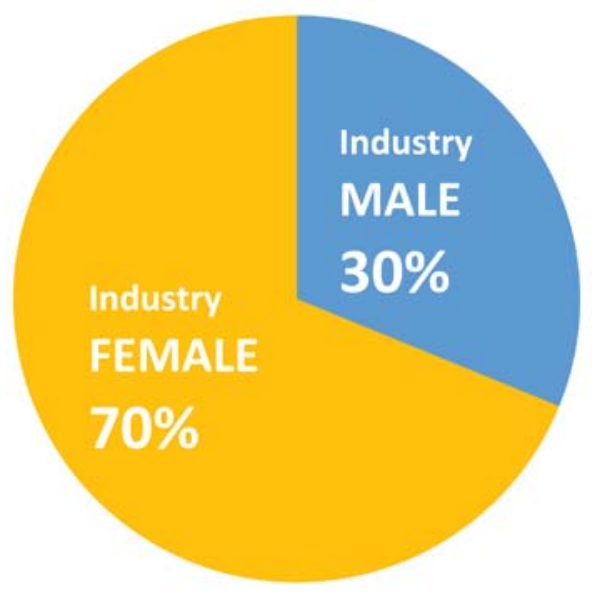

\section{GIG BUDDIES VOLUNTEERS - GENDER}

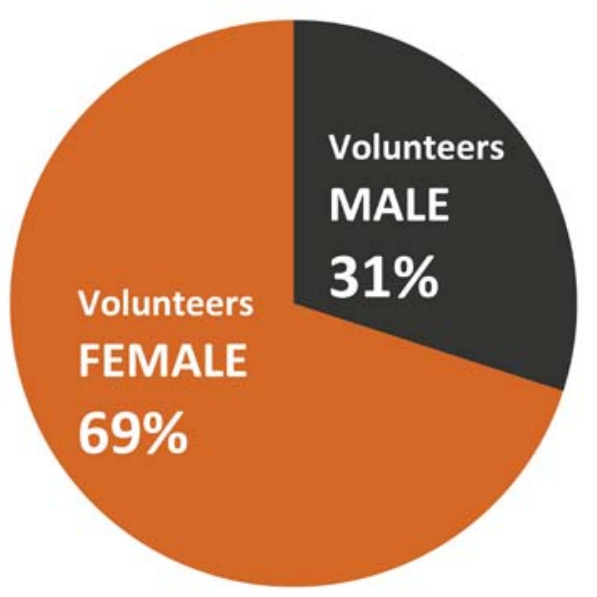

Figure 1. Gender—Disability Industry vs Gig Buddies Volunteers.

SUMMARY OF PARTICIPANTS AND VOLUNTEERS - GENDER - ALL AGES

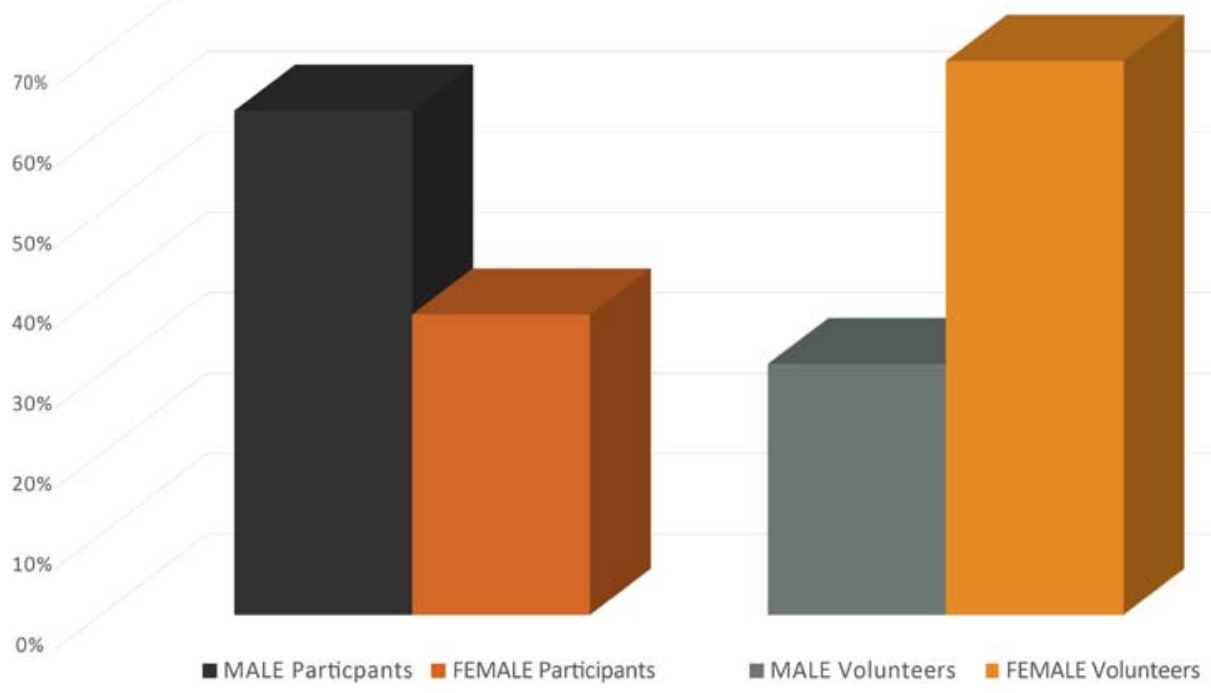

Figure 2. Gender-Participants and volunteers.

As you can see from the table (Figure 2), there are almost double the number of males to female participants.

Of these male participants, more than half requested a male volunteer (with very few requesting a female buddy), which would suggest there is a definite need and want for male role models for males with learning disability.

For male volunteers, particularly those in a younger age group, the project can be an entry to the disability sector 
as well as an opportunity to challenge the stereotype and perception of volunteer participation being largely a feminine pursuit or by those who have retired.

SUMMARY OF PARTICIPANTS AND VOLUNTEERS - GENDER - AGE GROUPS

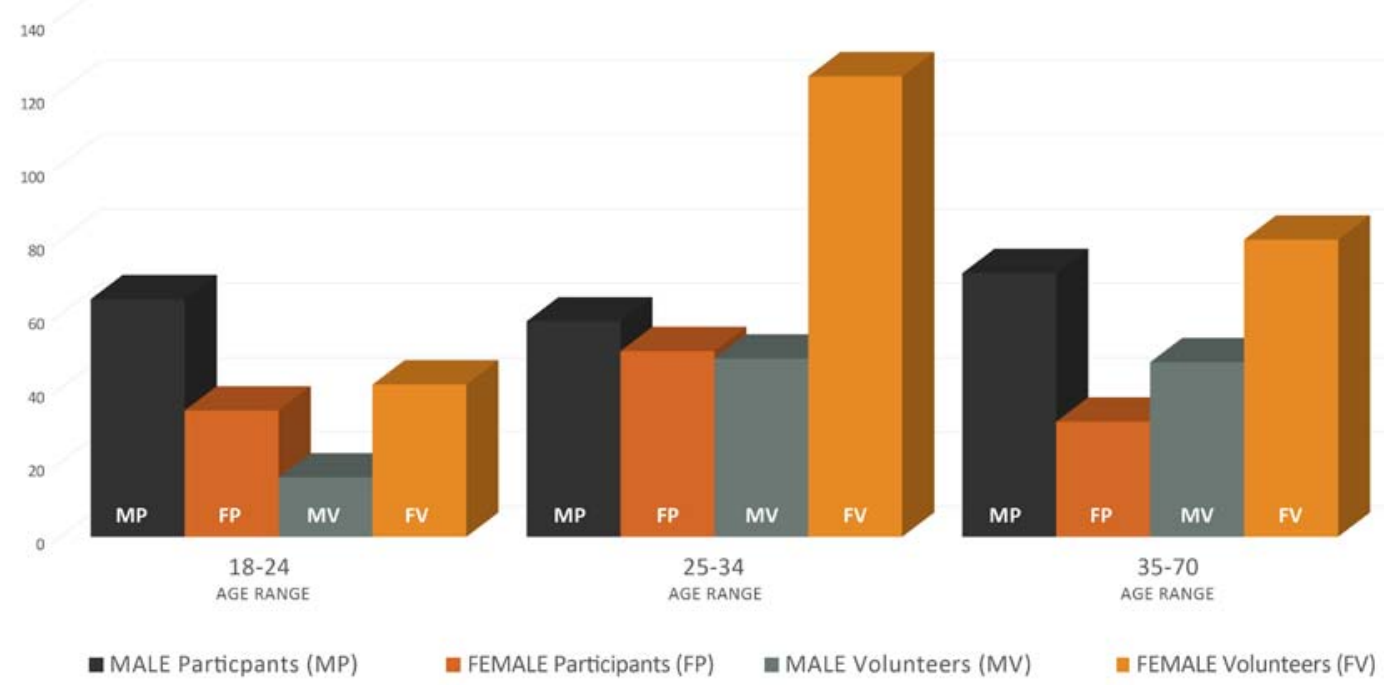

Figure 3. Gender \& age groups-Participants and volunteers.

The promising statistic from the breakdown of age groups amongst volunteers and participants is the high proportion of male and female volunteers in the 25-to-34-year age bracket (see Figure 3).

According to the July 2017 NDS Australian Disability Workforce Report;

"The disability workforce in Australia is overrepresented by people 45 years and over, with nearly a quarter of the disability workforce aged between 45 and 54 years, compared to $21 \%$ of the all-industry employed workforce."

and

"Seeing as $70 \%$ of an organisations workforce is female, and that the average retirement age for females is 60.4 years ${ }^{2}$, the disability support sector is facing an aging workforce at the same time as growing demand for workers."

1. Australian Bureau of Statistics, Labour Force, Australia, Detailed, Quarterly, Feb 2017, Cat no. 6291 .0.55.003 (Table 26b).

2. Australian Bureau of Statistics, Retirement and Retirement Intentions, Australia, July 2014 to June 2015, Cat. No. 6238.0, average age at retirement for persons who have retired in the previous five years.

The introduction of a considerable proportion of volunteers in the 25-to-34-year age bracket, both female and male, to the disability industry, through volunteer programs such as Gig Buddies may, in time help to replenish the stocks of an aging workforce and help meet the current and future needs of the sector.

The publicity the program has received from traditional media outlets as well as new media, has highlighted the problem of social isolation of people with learning disability, but has also destigmatised what it means to work with, or be friends with, a person with a disability.

Through community engagement and positive social sentiment, the project is changing people's reaction to working in the disability sector from "That must be very rewarding, but I could never do that", to "wow, that looks like fun" and "I think I could do that!!"

Project statistics show that $95 \%$ of volunteers for Gig Buddies have no previous experience working with people with learning disability and $60 \%$ have never volunteered before.

Volunteers involved with the project, either as active volunteers attending gigs with their buddies, or attending the open house Gig Buddies social events, can gain experience by interacting with people with learning disability with the guidance and support of other volunteers and the Gig Buddies Sydney project facilitators. 
Direct or indirect learnings about social inclusion and community participation for people with disability, through an engaging and immersive project such as Gig Buddies, can encourage further participation, professionally or voluntarily, in the disability sector for male and female volunteers. This increased participation and engagement of new, inexperienced people, can potentially, over time, create a more diverse and gender inclusive workforce.

\section{National Disability Insurance Scheme-NDIS}

With the recent introduction of the NDIS in Sydney and other parts of Australia, the way disability services are accessed has been radically changed.

With NDIS clients now actively searching for new services, the marketplace for disability providers needs to evolve, and a more gender diverse labour pool is needed to meet the demands of clients.

"Anticipated shortages of both aged care and disability care workers require specific strategies to be developed to encourage non-traditional labour pool, such as men, into the sector”.

(Hugo 2007)

According to Better Caring founder Peter Scutt,

"Since the NDIS arrived, more than half the people searching for services have done so based primarily on the provider's gender.

(Peter Scutt, Better Caring, 2017)

(Verity Edwards, The Australian 12:10am July 8, 2017)

Scutt attributes this to younger people with disability wanting a carer they can relate to rather than motherly figures - who have traditionally taken on caring roles — and many seek male role models.

"For men it was never seen as a valued role and it was typically left to women to do these caring roles, and it's important for people to find the right care worker."

"The workforce was built on a model of providing care and support but the service option was limited. We're giving NDIS participants purchasing power and they're going to demand a male.

“A 17-year-old doesn't want care from a woman who reminds him of his mum, he might want someone he shares interests with."

(Peter Scutt, Better Caring, 2017)

According to Flinders University associate professor Debra King, men rarely enter the caring workforce from school, and most found jobs later in life after a job change, interstate move, sometimes after caring for a child with a disability or a sick partner who had died.

Volunteer programs such as Gig Buddies can be a rewarding and appealing way for young males to be introduced to the industry and gain disability experience from an earlier age.

\section{Personal care vs. social engagement}

As the NDIS rollout continues, the disability sector is witnessing an emphasis on personal care services in participants funding packages at the expense of social and community integration and engagement.

From experience with ACL Disability Service clients and Gig Buddies participants, there has been a lack of individual NDIS funds in clients' packages for capacity building, which includes mentoring peer support and individual skill development.

"The most terrible poverty is loneliness and the feeling of being unloved.” Mother Teresa

Funding for core personal care services is essential, but it could be argued that living without inclusive and personalised social interactions is merely surviving.

The choice and control that the National Disability Insurance Scheme allows for, and the introduction of creative and innovative volunteer befriending and mentoring programs such as Gig Buddies, can encourage diversity and address gender imbalance in the disability sector. In the future, as more people become aware of the rewarding nature of working with or befriending a person with a disability, a more diverse workforce may meet the demands of 
the sector.

\section{Addendum-February 2022}

Since this paper was presented at Gender, Work and Organisation, $10^{\text {th }}$ Biennial International Interdisciplinary Conference, Sydney, 13-16 June 2018, the Gig Buddies project has continued to grow and develop. The project now incorporates the Central Coast region in NSW and the Greater Sydney region.

Since it's inception in 2015, the project has facilitated 385 Gig Buddy pairings, with some buddy friendships continuing for over 6 years. In order to sustain community connections during the COVID-19 pandemic, the project adjusted the service model to include regular online social events (up to 5 times per week), and increased socially distanced, small group gatherings when permitted by NSW Government regulations. Volunteer training, participant introductory meetings and pairing meetings were modified accordingly and taken online during lockdowns. Despite the challenges, the project was able to connect 90 participants with volunteers in 2020, and 100 in 2021, and train 103 volunteers in 2020 and 95 in 2021. The project hosted 142 social events (98 online \& 44 face-to-face) in 2020, and 134 social events (88 online \& 46 face-to-face) in 2021.

\section{References}

Australian Bureau of Statistics, Labour Force, Australia, Detailed, Quarterly, Feb 2017, Cat no. 6291.0.55.003 (Table 26b).

Australian Bureau of Statistics, Retirement and Retirement Intentions, Australia, July 2014 to June 2015, Cat. No. 6238.0, average age at retirement for persons who have retired in the previous five years.

Australian Institute of Health and Welfare (AIHW), 2004.

Australian Journal of Social Issues (Australian Council of Social Service), 42(2), 169-182.

Bigby, et al. (2017). (LaTrobe University, Living with Disability Research Centre), “Identifying conceptualizations and theories of change embedded in interventions to facilitate community participation for people with intellectual disability: A scoping review”.

Hugo. (2007). Contextualising the 'Crisis in Aged Care' in Australia: A Demographic Perspective.

Peter Scutt, Better Caring, 2017.

Verity Edwards, The Australian 12:10 am July 8, 2017. 